\title{
INTERPRETATIVE TRANSLATION THEORY AND ITS EVALUATION BY RUSSIAN AND FOREIGN TRANSLATORS AND TRANSLATION STUDIES SCHOLARS ${ }^{1}$
}

\author{
Olga I. Popova \\ Volgograd State University, Volgograd, Russian Federation \\ Aleksandr S. Besedin \\ Volgograd State University, Volgograd, Russian Federation \\ Anna P. Naumova \\ Volgograd State University, Volgograd, Russian Federation
}

\begin{abstract}
This article analyzes the current status of the interpretative translation theory, which, compared to other translation theories, does not study the result of translation, with its dependence on multiple factors, but instead focuses on the process of translation, which does not differ depending on the language and remains the same for all types of translation and text types. The authors draw attention to the evaluation of this theory by various translation schools: French school, where the theory is universally acknowledged and accepted, taking into account the fact that this school is represented by E.S.I.T. (High School of Interpretation and Translation, Paris, France) graduates; former French colonies, where the French language has lost its influence but remains demanded in science and education (for instance, Vietnam), Canadian (English-speaking) and Russian translation schools.

This work outlines the ambiguous attitude to the interpretative translation theory by many leading Russian scholars; certain discrepancies in its understanding by Canadian translation studies specialists, who pay more attention to translation issues and partially depart from the main principles of the interpretative theory. Besides, it studies the works of researchers from other countries, who have written their articles in English. The article analyzes both theoretical approaches and attitude to the interpretative translation theory of practicing translators and interpreters and provides their evaluation of this theory as a regularly applied translation technology.

Key words: translation theory, interpretative theory, translation studies, professional discourse, evaluation, culture translation, cultural transfer.

Citation. Popova O.I., Besedin A.S., Naumova A.P. Interpretative Translation Theory and Its Evaluation by Russian and Foreign Translators and Translation Studies Scholars. Vestnik Volgogradskogo gosudarstvennogo universiteta. Seriya 2, Yazykoznanie [Science Journal of Volgograd State University. Linguistics], 2017, vol. 16, no. 3, pp. 58-70. (in Russian). DOI: https://doi.org/10.15688/jvolsu2.2017.3.6

\section{ИНТЕРПРЕТАТИВНАЯ ТЕОРИЯ ПЕРЕВОДА В ОЦЕНКАХ ОТЕЧЕСТВЕННЫХ И ЗАРУБЕЖНЫХ ПЕРЕВОДЧИКОВ И ПЕРЕВОДОВЕДОВ ${ }^{1}$}

\author{
Ольга Ильинична Попова
}

Волгоградский государственный университет, г. Волгоград, Российская Федерация 


\section{Александр Сергеевич Беседин}

Волгоградский государственный университет, г. Волгоград, Российская Федерация

Анна Петровна Наумова

Волгоградский государственный университет, г. Волгоград, Российская Федерация

Аннотация. В статье рассматривается современное состояние интерпретативной теории перевода (ИТП), в отличие от многих других теорий исследующей не результат перевода, на который влияют многочисленные факторы, а процесс перевода, не зависящий от языка, способов перевода и типов текстов. Внимание авторов сфокусировано на оценке функционирования этой теории в различных переводческих школах: франкоговорящих, где теория принимается и поддерживается, поскольку эти школы представлены выпускниками E.S.I.T. Высшей школы переводчиков г. Париж (Франция); в бывших колониях Франции, где французский язык утратил свое влияние, но остается востребованным в науке и образовании (например, Вьетнам); в англоговорящей канадской и отечественной переводческих школах.

В работе делается акцент на неоднозначном отношении многих ведущих российских ученых к интерпретативной теории перевода; отмечаются различия в понимании интерпретативной теории канадскими переводоведами, уделяющими большее внимание вопросам письменного перевода и частично отходящими от основных постулатов ИТП; характеризуются англоязычные работы исследователей из других стран, рассматривающих содержание ИТП. В статье, наряду с теоретическими подходами, анализируется отношение к ИТП практикующих переводчиков, приводится их оценка данной теории как регулярно применяемой технологии перевода.

Ключевые слова: теория перевода, интерпретативная теория, переводоведение, профессиональный дискурс, оценка, перевод культуры, культурный трансфер.

Цитирование. Попова О.И., Беседин А.С., Наумова А.П. Интерпретативная теория перевода в оценках отечественных и зарубежных переводчиков и переводоведов // Вестник Волгоградского государственного университета. Серия 2, Языкознание. - 2017. - Т. 16, № 3. - С. 58-70. - DOI: https://doi.org/10.15688/ jvolsu2.2017.3.6

Среди многочисленных теорий перевода, появившихся во второй половине XX столетия, особого внимания заслуживает интерпретативная теория (далее - ИТП), созданная теоретиком переводоведения и переводчиком-практиком Даницей Селескович (Danica Selescovitch). Основные постулаты этой теории были отражены в ее публикациях 80-х гг. и стали базовыми для французской переводческой школы E.S.I.T.

Интерпретативная теория перевода рассматривает не результат перевода, который может зависеть от многочисленных факторов (форма источника - устный или письменный, его жанр, сфера функционирования и т. д.), а процесс перевода, который не дифференцируется в зависимости от языка, способов перевода и типов текстов. Согласно этой теории процесс перевода должен осуществляться в три этапа: понимание смысла, фаза девербализации (то есть отказ от слов и предложений, которые породили смысл), во время ко- торой смысл существует без конкретной лингвистической опоры, и выражение этого смысла на другом языке [Selescovitch, Lederer, 2002]. Понимание смысла как определяющего фактора переводческой деятельности привело к отрицанию роли прямых соответствий, поскольку, чтобы понять смысл речи, ее нужно девербализировать.

Столь революционный взгляд на теорию перевода не мог быть сразу принят всем переводческим сообществом. Эта теория нашла поддержку прежде всего среди учеников французской переводческой школы, а затем во франкоговорящих странах и бывших колониях Франции.

Так, во Вьетнаме основные принципы интерпретативной теории, направленной в большей степени на синхронный и последовательный перевод, были применены при переводе художественной литературы. Основная задача переводчиков в данном случае - донесение до европейцев культурных особенностей страны через перевод художественных произведений - не могла быть успешно ре- 
шена с помощью традиционных (лингвистических) подходов, заключающихся в исключительно правильном построении фраз, в как можно более точной передаче значений конкретных слов. По мнению вьетнамского специалиста в области теории и практики перевода Динх Хонг Ван, «плохое качество переводов объясняется различными причинами, одной из них является расстояние между культурой, в которой оригинальный текст был создан, и той, для которой его переводят» (фр. «Cette qualité mauvaise de traduction s'explique par diverses raisons, l'une d'elles résultant des difficultés posées par la distance entre la culture dans laquelle le texte original a été rédigé et celle dans laquelle il est traduit») [Van, 2010, p. 142] (здесь и далее перевод цитат наш. - $О$. П., A. Б., A. H.).

Как переводить культуру? Многие десятилетия этот вопрос стоял перед вьетнамскими переводоведами. Только обращение к теории Парижской школы, как часто называют ИТП в Индокитае, позволило решить задачу создания переводов, адекватных оригинальным иноязычным текстам.

Интерпретативная теория перевода оказалась востребованной при подготовке переводчиков в Португалии. Франсуаз Бодене, член Международной ассоциации конференцпереводчиков и преподаватель устного перевода в университете провинции Минхо, описывая свой опыт подготовки переводчиков, работающих с португальским языком, активно использует в качестве примеров многочисленные упражнения по девербализации и вычленению смысла, ссылаясь на школу E.S.I.T. [Bodenez, p. 282].

В отечественном переводоведении публикации, в которых характеризуется интерпретативная теория перевода, можно условно разделить на две группы: 1) работы (в основном учебно-практической направленности), в которых ИТП анализируется наряду с другими теориями перевода, при этом, как правило, подчеркивается ее ориентированность преимущественно на устный перевод; 2) работы, в которых обосновывается значимость ИТП, раскрываются ее возможности в сфере пись- менного (в частности, художественного) перевода.

2.1. К первой группе относится учебное пособие авторитетного отечественного переводоведа В.Н. Комиссарова «Общая теория перевода» (1999). Оно направлено на ознакомление учащихся с наиболее значимыми на момент написания книги переводческими подходами и теориями, сложившимися в зарубежной науке, в число которых входит и интерпретативная теория. При этом в рамках ИТП В.Н. Комиссаров рассматривает не только идеи Д. Селескович и французского переводоведа М. Ледерер (М. Lederer), но и их последующее развитие в работах канадского исследователя Ж. Делиля (J. Delisle). Положения Д. Селескович, по словам В.Н. Комиссарова, имеют в своей основе «неоспоримые лингвистические и психологические факторы, раскрывающие связь языка и мышления в процессе общения между людьми» [Комиссаров, 1999 , с. 38], а также предложенное $\Phi$. де Соссюром разделение языка и речи, возможность варьирования смысла высказывания в зависимости от таких экстралингвистических факторов, как ситуация и контекст общения. Следовательно, основной задачей переводчика Д. Селескович считает передачу смысла высказывания, которая решается прежде всего в рамках устного, в особенности синхронного, перевода, однако принцип «перенесения смысла» может быть использован, несмотря на затрудняющие факторы, и в письменном переводе. Таким образом, по утверждению В.Н. Комиссарова, из своей концепции «Д. Селескович делает далеко идущие выводы» [Комиссаров, 1999, с. 39].

Вклад М. Ледерер в развитие идей Д. Селескович, как считает В.Н. Комиссаров, состоит в распространении на иные виды перевода возможностей, предоставляемых синхронным переводом, и понимании передачи смысла как наиболее приоритетной задачи; в выдвижении концепции взаимоотношений объекта и одного из его признаков, выражаемых с помощью слова, как разновидности синекдохи. Поскольку синекдотические отношения свойственны и высказыванию, и тексту в целом, следовательно, с точки зрения М. Ледерер, переводчик может абстрагироваться от значений от- 
дельных слов в пользу понимания смысла переводимого текста.

Изложив основные идеи ИТП, В.Н. Комиссаров высказывает ряд критических замечаний. Прежде всего он подчеркивает гипертрофированность и ограниченность концепций, отводящих ключевую роль «интуитивнонепосредственному в речи», а также преувеличенное, на его взгляд, значение устного перевода в рамках ИПТ, не учитывающее более высокие требования к точности письменного перевода. Критике подвергается подход к высказыванию как явлению, носящему мгновенный и субъективный смысл, и утверждается, что оно должно содержать некую общую для носителей языка информацию, ведь именно понимание языковых единиц позволяет переводчику понимать смысл высказывания. Однако В.Н. Комиссаров замечает, что, несмотря на свои недостатки, теоретическая концепция Д. Селескович затрагивает важнейшие аспекты переводческого процесса и составляет несомненный научный интерес [Комиссаров, 1999, с. 44].

При представлении идей Ж. Делиля В.Н. Комиссаров одним из немногих увидел в нем «деятельного» исследователя, поскольку охарактеризовал вклад Ж. Делиля в развитие ИТП и частичный отход от них. (Однако другие исследователи предпочитали ограничиться рассмотрением ИТП в рамках работ Д. Селескович и М. Ледерер.)

Итак, Ж. Делиль разделил процесс перевода на три стадии:

- понимание, включающее в себя декодирование знаков, содержащихся в исходном тексте, извлечение смысла с учетом коммуникативной ситуации и контекста и требующее предварительного ознакомления со всем текстом понимание заголовка;

- перевыражение исходного текста средствами языка перевода, состоящее из определения схожести понятий в двух языках и перевербализации как подбора различных переводческих вариантов для последующей оценки;

- подтверждающий анализ, представляющий собой оценку полученных на предыдущем этапе переводческих вариантов на основании различных факторов и их последующую корректировку.
В.Н. Комиссаров анализирует предложенные Ж. Делилем упражнения для переводчиков, отмечая их ориентированность на решение прежде всего коммуникативных, а не языковых задач, что позволяет, во-первых, формировать отношение к тексту как к реальному, контекстуально и ситуативно обусловленному явлению, а не набору языковых единиц, во-вторых, научиться видеть и осознавать различие между значением и смыслом, при этом развивая способность создавать, анализировать и выбирать правильные соответствия. Таким образом, В.Н. Комиссаров отмечает, что, несмотря на следование положениям ИТП, работы Ж. Делиля «избегают крайностей этой концепции» и «свидетельствуют о возможности сближения различных переводческих теорий» [Комиссаров, 1999, с. 47].

Оценка интерпретативной теории перевода, представленная В.Н. Комиссаровым, и в частности его критические замечания, оказали влияние на отношение к данной концепции в отечественной учебно-практической литературе. В качестве примера можно рассмотреть учебное пособие В.В. Сдобникова и О.В. Петровой «Теория перевода» (2007), ориентированное на учащихся гуманитарных отделений вузов. В нем интерпретативная теория перевода характеризуется в разделе, посвященном проблемам описания переводческого процесса. Следует отметить, что авторы во многом опираются на «Общую теорию перевода» В.Н. Комиссарова и представленную там точку зрения. В.В. Сдобников и О.В. Петрова излагают базовые положения ИТП с опорой на работы Д. Селескович и М. Ледерер, в которых постулируется ключевая роль интерпретации исходного текста как понимания его смысла в противовес пониманию отдельных единиц языка, значимость процесса девербализации как отказа от направленности на перевод конкретных слов в пользу извлечения смысла рассматриваемого фрагмента, а также определяется статус устного перевода как представляющего наибольшие возможности для осуществления процессов интерпретации и девербализации.

При этом авторы учебника подробно характеризуют обозначенные В.Н. Комиссаровым недостатки: во-первых, критикуют приоритет фактора интуитивности, поскольку 
сложные тексты нуждаются в сознательном и объективном анализировании и именно переводчику письменных текстов в силу специфики его деятельности предоставляется больше возможностей такого анализа текста по сравнению с устным переводом, проходящим в экстремальных условиях и менее требовательным к ошибкам, потерям и отклонениям от оригинала, во-вторых, критикуют приоритет субъективного смысла и сиюминутности высказывания, поскольку смысл высказывания, согласно В.Н. Комиссарову, основывается на его языковом содержании и, помимо субъективного смысла, оно должно передавать и некую общую для пользователей языка информацию, обратное сделало бы процесс коммуникации невозможным. Однако, несмотря на подробное рассмотрение критических замечаний в отношении ИТП и объемное цитирование работы В.Н. Комиссарова, авторы отмечают и значимые положительные стороны данной концепции, в частности важную роль девербализации как одной из составляющих переводческого процесса, которая предоставляет возможность абстрагироваться от языкового выражения содержания высказывания, тем самым позволяя преодолеть «интерференцию в переводе» [Сдобников, Петрова, 2007 , с. 250$]$ и ориентироваться на нормы (включая узуальные) языка перевода. Характеризуя значимость предложенной в рамках интерпретативной теории перевода идеи девербализации, В.В. Сдобников и О.В. Петрова утверждают, что роль девербализации важна и абсолютно реализуема в условиях и письменного, и устного перевода [Сдобников, Петрова, 2007, с. 250].

Неоднократно обращалась к рассмотрению интерпретативной теории перевода И.С. Алексеева. Так, в учебном пособии «Введение в переводовение» (2004) она, несмотря на отсутствие подробного анализа данной переводческой концепции, упоминает ряд идей, выдвинутых Д. Селескович и М. Ледерер. Однако помимо этого в одном из начальных разделов пособия, посвященном описанию основных образовательных учреждений, занимающихся профессиональной подготовкой специалистов в области перевода, при перечислении учебных заведений подобной направленности во Франции наибольшее внимание уделено особенностям E.S.I.T. - Высшей школы устных и письменных переводчиков: наличию отделений письменного и устного перевода и различиям используемых ими образовательных программам. При этом И.С. Алексеева упоминает, что на отделении устного перевода основополагающей методикой является именно «теория смысла», разработанная Д. Селескович, и отмечает, что в связи с этим на первом курсе будущие специалисты в сфере устного перевода занимаются пересказыванием текстов, непосредственно к переводу приступают на втором курсе, а навыки двуязычного конференцперевода совершенствуют на последнем, третьем, курсе обучения.

В пособии И.С. Алексеевой имя Д. Селескович упоминается и в главе, посвященной рассмотрению теоретических проблем, связанных с переводческим процессом, описывается основанная на анализе синхронного перевода идея, согласно которой восприятие как стадия процесса перевода должно совершаться без учета языкового содержания, в то время как вторая стадия перевода - воспроизведение - заключается в работе с идеями и смыслом высказывания; при этом И.С. Алексеева отмечает, что «Д. Селескович отрицает этап анализа в устном переводе и ставит под сомнение результаты письменного перевода» [Алексеева, 2004, с. 148] ввиду высокого риска потери заложенного в тексте смысла при анализе текста и его языковых знаков. В главе, посвященной фонетическим проблемам перевода, при анализе восприятия фонетического облика текста и эквивалентности устного перевода утверждается, что методика Д. Селескович и М. Ледерер предоставляет возможность не только определить заложенные в высказывании основные и второстепенные смыслы максимально точным образом, но и выразить их в свободной форме. Идеи ИТП упоминаются и в главе, освещающей переводческие стратегии: Д. Селескович и М. Ледерер названы в ряду теоретиков, занимающихся разработкой данного, относительно нового, понятия; кроме того, в качестве «особенно ценных» достижений анализа переводческой стратегии как последовательности осуществляемых в ходе переводческого процесса действий И.С. Алексеева характе- 
ризует обозначенные М. Ледерер комбинации восьми операций, совершаемых синхронистами, и отмечает, что кроме контроля переводчика за собственной речью все они применимы и к письменному переводу. Отметим, что в данном разделе упоминается и имя Ж. Делиля, выдвинувшего собственную классификацию этапов переводческой деятельности.

Впоследствии И.С. Алексеева более тщательно проанализировала положения ИТП, в частности, в рамках статьи «Место интерпретативной теории в современной теории и практике перевода». В ней описываются исторические предпосылки возникновения данной концепции, ее базовые постулаты и слабые стороны, а также ее влияние на использующиеся в современной переводческой деятельности методики.

Так, И.С. Алексеева отмечает, что, несмотря на провокационный характер идей Д. Селескович и М. Ледерер на момент их возникновения, когда доминировали подходы, направленные на рассмотрение проблематики письменного перевода, у этой концепции были предпосылки: во-первых, это идеи авторитетного советского переводчика И. Кашкина, предложившего в рамках своей так называемой теории «реалистического перевода» абстрагироваться от формального содержания текста в пользу заложенных в нем идей; вовторых, сформировавшиеся в 1950-х гг. взгляды Ж. Мунена (G. Mounin) и Э. Кари (E. Cary), в-третьих, как отмечала М. Ледерер, это деятельность 3. Фрейда.

Таким образом, несмотря на новаторский характер ИТП, подобные подходы уже существовали в теории и практике перевода, кроме того, данная теория отчасти базируется на уже сложившихся концепциях. При этом, как подчеркивает И.С. Алексеева, интерпретативная теория перевода обладает новизной, которая заключается не только в выборе рассматриваемого предмета (с учетом доминантного характера письменного перевода в качестве предмета изучения), но и в предлагаемой научной парадигме, заключающейся в отказе от связки «язык - перевод» и переходе к речевому процессу.

Анализируя слабые места ИТП, И.С. Алексеева опирается на позицию В.Н. Комиссарова и аргументирует наличие выявленных им недостатков тем фактом, что на момент возникновения данной теории в науке о переводе отсутствовали представления о типологии текстов, в связи с чем, по ее мнению, при рассмотрении ИТП следует учитывать исторический контекст.

Оценивая актуальность ИТП с позиций современного переводоведения, И.С. Алексеева отмечает, что задача идентификации языка и речи, о которой писала М. Ледерер, на сегодняшний день во многом решена благодаря развитию в 1980-90-е гг. теории текста. С момента возникновения ИТП (1960-е гг.) в связи с развитием теории интерпретации текста изменились представления и об интерпретации как моментальном мыслительном действии, связанном с вычленением смысла: в статье И.С. Алексеевой отражается позиция И.В. Арнольд о вариативности интерпретации и диалогичности понимания текста и отмечается вклад в развитие понятия интерпретации такими направлениями, как теория интертекстуальности и герменевтика. Кроме того, спорной в ИТП является трактовка самого понятия «смысл».

И.С. Алекссева рассматривает в пособии и методику обучения переводу, разработанную Д. Селескович и М. Ледерер на основе их теории, отмечая значимость способности интерпретации текста и его главных смысловых составляющих, активизирующей вариативность речевого перевода и придающей уверенности переводчику, что является весьма полезным при переводе письменных текстов, содержащих сюжетные элементы, и устных текстов, обладающих открытой структурой, но при этом утверждая, что данная методика не предоставляет возможности в полной мере овладеть профессиональным переводом. В частности, И.С. Алексеева упоминает понятие транскодирования, введенное C. Калина (S. Kalina) и заключающееся в передаче чисел, имен собственных, терминов, конвенциональных формулировок и т. д. на поверхностном уровне. Кроме того, И.С. Алексеева замечает, что при использовании только методики ИТП могут возникнуть серьезные трудности при переводе текстов, обладающих интертекстуальностью, то есть содержащих цитаты, аллюзии, отсылки и т. п., а также при дипломатическом переводе, ка- 
тегорически не допускающем возможности перефразирования высказывания. Следовательно, И.С. Алексеева показывает, что понимание смысла высказывания и способность его передачи в ряде случаев является далеко не единственным выдвигаемым к переводчику требованием.

В выводах к статье утверждается, что, несмотря на новаторство интерпретативной теории перевода, она не носит исчерпывающего характера, который позволил бы раскрыть все аспекты переводческого процесса, и представляет собой основу «одного из сегментов современной комплексной методики обучения переводу» [Алексеева, 2011, с. 206].

2.2. В работах второй группы выявляются возможности ИТП, которые она открывает для усовершенствования переводческого процесса и его результатов. В первую очередь отметим исследования Т. Бодровой-Гоженмос (филолога российского происхождения): диссертацию по теории перевода, выполненную под руководством М. Ледерер и защищенную в E.S.I.T., и ряд статей на русском языке (оригинальных и переведенных с французского).

Мы решили уделить особое внимание ее статье «Концепция М.М. Бахтина и интерпретативная теория перевода», вышедшей в 2002 г. в «Вестнике Воронежского государственного университета», поскольку данная работа представляет собой переведенный с французского фрагмент защищенной в парижской Высшей школе переводчиков докторской диссертации. Как следует из заголовка, в данной работе Т. Бодрова-Гоженмос проводит параллели между ИТП и металингвистическими идеями М.М. Бахтина, отмечая, что хотя обе концепции сформировались независимо друг от друга, они имеют много схожих черт, в частности в подходе к тексту и / или высказыванию как нематериальному объекту, как проявлению сознания, передающему некий смысл.

Так, по М.М. Бахтину, гуманитарные науки исходят из понятия текста, представляющего собой субъективное высказывание, отражающее субъективное восприятие мира человеком. В связи с этим любое высказывание является уникальным, индивидуальным и завершенным, и его ключевая особенность наличие конкретного смысла, объединяюще- го формальные языковые единицы и реальность, и, хотя высказывание конструируется посредством языковой системы, оно уникально в силу наличия в нем смысла и авторского замысла. Этот подход близок идеям ИТП, также утверждающей, что текст - уникальное явление, наделенное заложенным в него смыслом: «предложенное русским ученым понятие текста как высказывания органично вписывается в интерпретативную концепцию перевода» [Бодрова-Гоженмос, 2002, с. 78], поскольку ориентировано на высказывание, его смысл и учет коммуникативной ситуации, требующей принятия во внимание играющих важную роль экстралингвистических факторов, при этом ИТП «применима для перевода текстов всех типов и жанров» [Бодрова-Гоженмос, 2002, с. 78].

Идеи сходства концепции российских исследователей и положений ИТП получили свое развитие и в других отечественных публикациях. Так, Т.М. Велла, рассматривая в статье «Переводческие константы интерпретативной теории перевода» стадию восприятия как первоначальный этап в рамках ИТП, также отсылает читателей к работам М.М. Бахтина, помимо этого обращаясь и к исследованиям Ю.М. Лотмана, разграничившего понятия «текст» и «произведение» ввиду наличия в последнем определенного контекста, учет которого является важным фактором для понимания содержащейся в тексте информации. Руководствуясь этим принципом, мы можем предположить, что понимание смысла становится предпосылкой второго этапа перевода, согласно ИТП - девербализации как восприятия смысла в целом, для последующего перевода на другой язык. Т.М. Велла приходит к выводу о том, что интерпретативная теория перевода «логично построена и опирается на положения, разработанные не только французскими, но и отечественными учеными-переводоведами» [Велла, 2013, с. 205], при этом подчеркивая широкие перспективы данной теории.

В другой публикации, выполненной Т.М. Веллой в соавторстве с Е.А. Алексеевой, характеризуются возможности достижения эквивалентности перевода художественного текста на основе положений ИТП. В ней также приводятся идеи М.М. Бах- 
тина и Ю.М. Лотмана о разграничении текста и произведения, соотносящиеся с требованием передачи смысла, провозглашаемым в рамках ИТП, и этапами понимания, девербализации и ревербализации как стадий переводческого процесса. Далее в качестве примера исследователи приводят ряд переводческих решений, принятых при переводе на русский язык романа Э. Базена «Змея в кулаке» (Herve Bazin «Vipère au poing»), и демонстрируют, как отказ от дословного перевода и перефразирование фрагментов оригинала позволяют передать смысл, заложенный автором в высказывание, и обеспечить его успешное донесение до иноязычной аудитории, то есть достичь максимальной эквивалентности оригинального и переводного текстов. При этом авторы статьи отмечают: несмотря на то что в работе рассматриваются примеры из художественного перевода, являющегося своего рода творческим процессом, «интерпретативная теория перевода дает универсальную модель для процесса перевода» и «основные положения интерпретативной теории перевода распространяются в одинаковой степени на все виды перевода... перевод любой тематической направленности и жанровой принадлежности» [Алексеева, Велла, 2015, с. 20].

Таким образом, ИТП подробно анализируется в отечественной научно-исследовательской и учебной литературе в двух направлениях: одни авторы рассматривают ИТП как переводческую концепцию, отмечая ее слабые стороны, ограниченность и узконаправленный характер; другие, напротив, акцентируют внимание на взаимосвязи ИТП с уже устоявшимися в гуманитарных науках концепциями, при этом актуализируя значимость данной теории и приводя доказательства заложенного в ней потенциала и предоставляемых ею возможностей для применения в переводческой деятельности во всех ее разновидностях.

3

Описание интерпретативной теории перевода в англоязычной литературе носит преимущественно обзорный характер, и ИТП, как правило, упоминается в различного рода энциклопедических ресурсах или публикациях, перечисляющих различные подходы, сложившиеся в науке о переводе. На наш взгляд, подобная ситуация может быть обусловлена, во-первых, тем фактором, что идея «теории смысла» получила свое широкое распространение во французской школе лингвистики и так или иначе смежных с нею школах (см. работы канадского переводоведа Ж. Делиля), а во-вторых, тем, что основополагающие труды по данному направлению (а именно работы Д. Селескович, М. Ледерер и Ж. Делиля) были переведены на английский еще в 80-е и 90-е годы.

Итак, в издании «Routledge Encyclopedia of Translation Studies» под редакцией М. Бейкер (M. Baker), представляющем собой энциклопедический ресурс, содержащий сведения об этапах в истории развития переводоведения и основных исследовательских подходах, неоднократно упоминается о влиянии идей Д. Селескович и М. Ледерер на развитие конференц-перевода и синхронного перевода, а также на осознание важности понимания высказывания в рамках переводческого процесca. Помимо этого, интерпретативному подходу в переводе посвящена отдельная статья, принадлежащая М. Салама-Карр (M. SalamaCarr), в которой описывается становление «теории смысла» в E.S.I.T. и влияние на нее психологии и нейропсихологии, излагаются основные понятия данной теории, а также демонстрируются различия между ИТП и понятием интерпретативного перевода британского ученого П. Ньюмарка (P. Newmark), который предложил методику перевода, ориентированную прежде всего на язык оригинала, а не на понимание текста иноязычной аудиторией. Кроме этого, в статье отмечается, что за последние годы влияние интерпретативного подхода возросло в письменном переводе, поскольку тот позволяет решить проблему непереводимости текста, в особенности в случае художественного перевода. В то же время М. Салама-Карр замечает, что, несмотря на значимость интерпретативного подхода, он достаточно редко рассматривается и анализируется в англоязычной научной среде, хотя основные труды в рамках данного подхода были переведены на английский [Routledge Encyclopedia of Translation Studies, 1998]. 
ИТП рассматривается также в книге «Simultaneous Interpretation: A cognitivepragmatic analysis» Р. Сеттона, которая посвящена вопросам синхронного перевода. В данной работе описывается деятельность «интерпретативной школы» переводоведения, базирующейся в Париже (при этом подчеркивается роль, которую сыграла Д. Селескович для становления профессионального устного перевода в Европе), излагаются основные положения «теории смысла», в частности подчеркивается необходимость знания переводчиком контекста, информации, не представленной в тексте, но значимой для понимания и, соответственно, перевода высказывания. Кроме того, Р. Сеттон обращает внимание на противопоставление интерпретативной теории перевода принятым на момент ее возникновения структуралистским и бихевиористким концепциям и отмечает их вклад в развитие понимания природы восприятия языка, а также открываемые ИТП новые возможности в плане устного перевода, в особенности синхронного и конференц-перевода [Setton, 1999].

В целом названные издания отражают общую тенденцию освещения интерпретативной теории перевода в научной среде англоязычных стран. Идеи «теории смысла» рассматриваются наряду с остальными переводоведческими концепциями, без акцентирования сильных или слабых сторон данного подхода, тем не менее исследователями отмечается важная роль этих идей и их влияние на развитие и становление перевода как профессиональной дисциплины; кроме того, наиболее значимые работы самых влиятельных приверженцев ИТП переведены на английский язык и, таким образом, представлены в данном пространстве.

Однако если расширить понятие англоязычных научных работ до всех публикаций, выполненных на английском языке (а ввиду процесса глобализации издание научных журналов на английском в иноязычных странах получило широкое распространение), то можно обнаружить рост внимания к интерпретативной теории перевода в Китае. Доказательством этому служат опубликованные в журнале «Canadian Social Science» и финском издании «Theory and Practice in Language
Studies» статьи китайских исследователей на английском.

Так, в статье «Application of the Interpretive Theory of Translation in Interpreting Practice» профессор Цян Канг из Чаньчуньского Научно-технологического университета, проанализировав основные положения ИТП, приходит к выводу о том, что, несмотря на долгую историю устного перевода в Китае, науке о переводе в стране не хватало эмпирических исследований, однако теперь китайское переводоведение имплементирует различные концепции, сформировавшиеся в западных странах, а ИТП внедряется в практику перевода с учетом современных требований, предъявляемых к переводчику (а именно: знания экстралингвистических факторов и контекста и, соответственно, умения извлекать смысл высказывания), а также ввиду важности для устного перевода способности переводчика передать смысл оригинального текста, частично игнорируя лингвистические формы [Kang, 2013].

Аналогичные идеи высказывает преподаватель факультета иностранных языков университета города Циндао Ю. Чжао в своей статье «The Feasibility Study of Interpretive Theories in the College English Course» [Zhao, 2014], посвященной рассмотрению возможностей, предлагаемых интерпретативной теорией перевода для обучения переводу с английского языка. Примечательно, что впервые работы Д. Селескович были переведены на китайский в конце 70-х гг., после чего китайские исследователели были направлены на обучение в E.S.I.T. и вышли публикации научных работ, посвященных интерпретативному подходу. Ю. Чжао считает, что за последние 30 лет внедрения ИТП удалось достичь значительных результатов не только в сфере устного перевода, но и в сферах перевода художественных, научных и иных текстов, а также в образовательном процессе. Ю. Чжао в своей статье предлагает модель обучения английскому языку на основе теории смысла, утверждая, что способность понимания смысла и переформулирования на его основе высказывания является одним из базовых навыков переводчика, в связи с чем важную роль в лингвистическом образовании может 
сыграть ИТП с ее понятиями девербализации и ревербализации.

В статье «An Empirical Study of Interpreting Quality with Interpretive Theory and Teaching Strategies» еe автор Ч. Дин, преподаватель факультета иностранных языков университета города Циндао, доказывает необходимость активного внедрения наработок ИТП в образовательный процесс, и в частности в обучение устному переводу, утверждая, что их применение позволит усовершенствовать качество подготовки будущих переводчиков [Ding, 2014].

Краткий обзор англоязычных источников подтверждает то, что интерес к интерпретативной теории перевода не ограничивается странами Западной Европы и Северной Америки, в которых возник и получил свое распространение данный подход.

\section{4}

Современная оценка интерпретативной теории перевода предполагает также обращение к профессиональной коммуникации практикующих переводчиков на эту тему. Форум, являясь одной из наиболее динамичных форм профессионального коммуникативного взаимодействия переводчиков, позволяет выполнить срез мнений представителей данного сообщества.

Вопросы, связанные с интерпретативной теорией перевода, обсуждаются с позиций методики перевода. Участники форумов используют данную площадку интеракции для самообразования и развития своих профессиональных навыков, например:

Bruno Fonseca: Je voudrais demander à mes collègues plus expérimentés... je suis à la recherche c'est d'un manuel qui pourrait me fournir des explications, règles et usages d'une façon pas trop théorique mais qui se baserait sur des exemples réels, vous rappelez-vous d'un bouquin en votre début de carrière qui vous aurait été utile?

Брюно Фонсека: Я хотел бы угочнить у своих более опытных коллег... я ищу учебник, в котором объяснения, правила и примеры приводились бы не в теоретизированном виде, а основывались бы на конкретных примерах; вспомните, может быть, в начале своей карьеры вы использовали какуюнибудь полезную книгу? (Здесь и далее перевод наш. - O. П., А. Б., А. Н.);
Stéphanie Soudais: À l'ESIT l'enseignement est basé sur la "théorie interprétative de la traduction" et les travaux de Danica Seleskovitch... c'est peut-être une piste.

Стефани Суде: Обучение в Высшей школе устных и письменных переводчиков построено на основе «интерпретативной теории перевода» и трудах Даницы Селескович... попробуйте поработать в данном направлении (Портал переводчиков «Proz.com». URL: http://www.proz.com/forum/french/ 210904-manuels_dinitiation_a_la_traduction_en_fr. html (дата обращения: 20.05.2017)).

Приведенные примеры иллюстрируют коммуникацию в направлении «начинающий переводчик» $\rightarrow$ «опытный переводчик» и нацелены на решение конкретной задачи: найти методический ресурс (я ищу учебник), который поможет в освоении практической переводческой деятельности (объяснения; на конкретных примерах; в начале карьеры). Автор вопроса получает от более опытного коллеги совет изучить возможность использования интерпретативной теории перевода, активно применяемой в Высшей школе устных и письменных переводчиков. Гетерогенность уровней квалификации эксплицитно представлена в исходном сообщении: Я хотел бы уточнить у более опытных коллег; вспомните... в начале своей карьеры вы использовали.

На форумах обсуждается эффективность реализации на практике положений теории перевода Д. Селескович, например:

My question, therefore, is 'as a professional translator*, do you believe that this Interpretive Theory of Translation could be utilised in your field of expertise on a day-to-day basis?' (*Translators only, please.) I look forward to hearing from fellow professional translators, especially those with greater experience than myself.

Мой вопрос заключается в следующем: «будучи профессиональным переводчиком*», считаете ли вы что данная интерпретативная теория перевода постоянно может применяться в вашей области знания? (*Вопрос адресован только переводчикам). Жду ответов от коллег, профессиональных переводчиков, особенно располагающих более богатым опытом, чем я (Портал переводчиков «Proz.com». URL: http://www.proz.com/forum/ translation_theory_and_practice/295435-discussion application_of interpretive theory in modern translation. html (дата обращения: 20.05.2017). 
Пользователь апеллирует к опыту коллег - профессиональных переводчиков, обладающих равной или более высокой квалификацией, чтобы узнать, используют ли они положения интерпретативной теории перевода в своей практической деятельности. При этом подчеркивается важность выполнения функций переводчика на профессиональной основе.

Интерпретативная теория также упоминается в контексте сопоставления с другими методиками устного перевода:

А вот почему было не воспользоваться опытом ESIT (Селескович), например. Ведь ее работы были в целом как раз о том, как переводить смысл, а не конструкции, что очень ложится на теорию «двух режимов» (Интернет-ресурс «Город переводчиков». URL: http://trworkshop.net/forum/ viewtopic.php? $\mathrm{f}=7 \& \mathrm{t}=56568 \& \mathrm{p}=921855 \& \mathrm{hilit}=$ селескович\#р921855 (дата обращения: 20.05.2017).

Анализируя технологию синхронного перевода (теорию «двух режимов»), существовавшую на различных этапах развития переводческого дела, участник форума предлагает использовать положения интерпретативной теории перевода (опытом $\operatorname{ESIT}$ (Ceлескович)), аргументируя при этом свою позицию (работыл.. как раз о том, как переводить смысл, а не конструкиии, что очень ложится на...).

Таким образом, теория перевода, разработанная во второй половине XX в., сохраняет свою актуальность и обсуждается представителями переводческого сообщества в рамках методического подхода с различных позиций: как отправная теоретическая точка практической деятельности и как регулярно применяемая технология перевода.

\section{4}

Несмотря на разработку основных постулатов ИТП в 80-е гг. XX в., она продолжает активно использоваться как теоретиками, так и практиками перевода. Франкоговорящие ее представители (преимущественно выпускники Высшей школы перевода E.S.I.T.) разрабатывают методические и дидактические аспекты. В англоязычном научном пространстве ИТП рассматривается в парадигме современных переводческих концепций. В оте- чественной научной и учебной литературе представлены оценки методического и дидактического аспектов ИТП, акцентируется внимание на применении ее положений в переводческой деятельности. Практикующие переводчики разных стран в рамках профессиональной коммуникации оценивают ИТП как эффективную.

\section{ПРИМЕЧАНИЕ}

${ }^{1}$ Исследование выполнено при финансовой поддержке Российского фонда фундаментальных исследований (РФФИ) и Администрации Волгоградской области, проект № 17-14-34001 «Региональный туризм как фактор формирования дискурса и технологии перевода: номинативные и коммуникативно-прагматические конвенции текстов брендинга» (Региональный конкурс «Волжские земли в истории и культуре России» 2017 - Волгоградская область).

\section{СПИСОК ЛИТЕРАТУРЫ}

Алексеева, Е. А. Достижение эквивалентности при переводе художественного текста (на основе опыта французской переводоведческой школы)/Е.А.Алексеева, Т. М. Велла // Филологические науки. Вопросы теории и практики. - 2015. - № 4. - С. 19-22.

Алексеева, И. С. Введение в переводоведение / И. С. Алексеева. - М. : Академия, 2004. - 352 с.

Алексеева, И. С. Место интерпретативной теории в современной теории и практике перевода / И. С. Алексеева // Язык и межкультурная коммуникация : материалы Второй Междунар. науч.практ. конф. (Великий Новгород, 19-20 мая 2011 г.) : в 2 т. - Великий Новгород : НовГУ им. Ярослава Мудрого, 2011. - Т. 2. - С. 202-206.

Бодрова-Гоженмос, Т. Концепция М.М. Бахтина и интерпретативная теория перевода / Т. Бодрова-Гоженмос // Вестник Воронежского государственного университета. Серия: Лингвистика и межкультурная коммуникация. - 2002. - № 3. - С. 72-79.

Велла, Т. М. Переводческие константы интерпретативной теории перевода / Т. М. Велла // Известия Воронежского государственного педагогического университета. - 2013. - № 2. - С. 204-206.

Комиссаров, В. Н. Общая теория перевода / В. Н. Комиссаров. - М. : ЧеРо, 1999. - 136 с.

Сдобников, В. В. Теория перевода / В. В. Сдобников, О. В. Петрова. - М. : АСТ: Восток-Запад, 2007. $-448 \mathrm{c}$.

Bodenez, F. La formation d'interprètes de conférence à l'Université de Minho. - Electronic text 
data. - Mode of access: http://ler.letras.up.pt/uploads/ ficheiros/6092.pdf(date of access: 26.04.2017). - Title from screen.

Ding, C. An Empirical Study of Interpreting Quality with Interpretive Theory and Teaching Strategies / C. Ding // Theory and Practice in Language Studies. - 2014. - Vol. 4, № 12. - P. 2466-2471.

Kang, Q. Application of the Interpretive Theory of Translation in Interpreting Practice / Q. Kang // Canadian Social Science. - 2013. - Vol. 9, № 6. P. 236-241.

Routledge Encyclopedia of Translation Studies / Ed. by M. Baker. - London : Taylor \& Francis Group, 1998. -654 p.

Selescovitch, D. Pédagogie raisonnée de l'interprétation / D. Selescovitch, M. Lederer. - Paris : Didier Erudion, 2002. -389 p.

Setton, R. Simultaneous Interpretation: A cognitive-pragmatic analysis / R. Setton. Philadelphia : John Benjamins Publishing Company, 1999. - 400 p.

Van, D. H. La théorie du sens et la traduction des facteurs culturels / D. H. Van // Synergie. Pays riverains du Mecong. - 2010. - № 1. - P. 141-171.

Zhao, Y. The Feasibility Study of Interpretive Theories in the College English Course - Exemplified with Qingdao University of Science and Technology / Y. Zhao // Theory and Practice in Language Studies.2014. - Vol. 4, № 8. - P. 1747-1752.

\section{REFERENCES}

Alekseeva E.A., Vella T.M. Dostizhenie ekvivalentnosti pri perevode khudozhestvennogo teksta (na osnove opyta frantsuzskoy perevodovedcheskoy shkoly) [Equivalence in Translation of Fiction Works (Based on Experience of the French Translation School)]. Filologicheskie nauki. Voprosy teorii i praktiki [Philological Sciences. Issues of Theory and Practice], 2015, no. 4, pp. 19-22.

Alekseeva I.S. Vvedenie $v$ perevodovedenie [Introduction to Translation Studies]. Moscow, Akademiya Publ., 2004. 352 p.

Alekseeva I.S. Mesto interpretativnoy teorii v sovremennoy teorii i praktike perevoda [Interpretative Theory in Modern Translation Theory and Practice]. Yazyk i mezhkulturnaya kommunikatsiya: materialy Vtoroy Mezhdunar. nauch.-prakt. konf. (Velikiy Novgorod, 19-20 maya 2011 g.): v 2 t. [Language and Intercultural Communication. Materials of the 2nd International Scientific Conference, Velikiy Novgorod,
May 19-20, 2011. In 2 vols. Vol. 2]. Velikiy Novgorod, NovGU im. Yaroslava Mudrogo, 2011, pp. 202-206.

Bodrova-Gozhenmos T. Kontseptsiya M.M. Bakhtina i interpretativnaya teoriya perevoda [M. Bakhtin's Conception in Interpretative Translation Theory]. Vestnik Voronezhskogo gosudarstvennogo universiteta. Seriya: Lingvistika i mezhkulturnaya kommunikatsiya [Proceedings of Voronezh State University. Series: Linguistics and Intercultural Communication], 2002, no. 3, pp. 72-79.

Vella T.M. Perevodcheskie konstanty interpretativnoy teorii perevoda [Translational Constants of Interpretative Translation Theory]. Izvestiya Voronezhskogo gosudarstvennogo pedagogicheskogo universiteta, 2013, no. 2, pp. 204-206.

Komissarov V.N. Obshchaya teoriya perevoda [General Translation Theory]. Moscow, CheRo Publ., 1999. $136 \mathrm{p}$.

Sdobnikov V.V. Teoriya perevoda [Translation Theory]. Moscow, AST, Vostok-Zapad Publ., 2007. $448 \mathrm{p}$.

Bodenez F. La formation d'interprètes de conférence à l'Université de Minho [Training of Interpreters at the Conference of the University of Minho]. URL: http://ler.letras.up.pt/uploads/ficheiros/ 6092.pdf. (accessed April 26, 2017).

Ding C. An Empirical Study of Interpreting Quality with Interpretive Theory and Teaching Strategies. Theory and Practice in Language Studies, 2014, vol. 4, no. 12, pp. 2466-2471.

Kang Q. Application of the Interpretive Theory of Translation in Interpreting Practice. Canadian Social Science, 2013, vol. 9, no. 6, pp. 236-241.

Baker M., ed. Routledge Encyclopedia of Translation Studies. London, Taylor \& Francis Group, 1998. 654 p.

Selescovitch D., Lederer M. Pédagogie raisonnée de l'interprétation [Rational Pedagogy of Interpretation]. Paris, Didier Erudion, 2002. 389 p.

Setton R. Simultaneous Interpretation: A cognitive-pragmatic analysis. Philadelphia, John Benjamins Publishing Company, 1999. 400 p.

Van D.H. La théorie du sens et la traduction des facteurs culturels [The Theory of Meaning and the Translation of Cultural Factors]. Synergie. Pays riverains du Mecong [Synergies. Countries Bordering the Mekong], 2010, no. 1, pp. 141-171.

Zhao Y. The Feasibility Study of Interpretive Theories in the College English Course - Exemplified with Qingdao University of Science and Technology. Theory and Practice in Language Studies, 2014, vol. 4, no. 8, pp. 1747-1752. 


\section{Information about the Authors}

Olga I. Popova, Candidate of Sciences (Philology), Associate Professor, Department of Translation Theory and Practice, Volgograd State University, Prosp. Universitetsky, 100, 400062 Volgograd, Russian Federation, tipp@volsu.ru, olgapopova@volsu.ru, http://orcid.org/0000-0001-9787-0317

Aleksandr S. Besedin, Postgraduate Student, Department of Translation Theory and Practice, Volgograd State University, Prosp. Universitetsky, 100, 400062 Volgograd, Russian Federation, tipp@volsu.ru, aleksandr-besedin@yandex.ru, http://orcid.org/0000-0002-5468-4677

Anna P. Naumova, Assistant Professor, Department of Translation Theory and Practice, Volgograd State University, Prosp. Universitetsky, 100, 400062 Volgograd, Russian Federation, tipp@volsu.ru, anaumova9@volsu.ru, http://orcid.org/0000-0003-4002-4915

\section{Информация об авторах}

Ольга Ильинична Попова, кандидат филологических наук, доцент кафедры теории и практики перевода, Волгоградский государственный университет, просп. Университетский, 100, 400062 г. Волгоград, Российская Федерация, tipp@volsu.ru, olgapopova@volsu.ru, http://orcid.org/0000-00019787-0317

Александр Сергеевич Беседин, аспирант кафедры теории и практики перевода, Волгоградский государственный университет, просп. Университетский, 100, 400062 г. Волгоград, Российская Федерация, tipp@volsu.ru, aleksandr-besedin@yandex.ru, http://orcid.org/0000-0002-5468-4677

Анна Петровна Наумова, старший преподаватель кафедры теории и практики перевода, Волгоградский государственный университет, просп. Университетский, 100, 400062 г. Волгоград, Российская Федерация, tipp@volsu.ru, anaumova9@volsu.ru, http://orcid.org/0000-0003-4002-4915 